\title{
Phyto-mellitus: A phyto-chemical database for diabetes
}

\author{
Sushil Kumar Middha ${ }^{1,2^{*}}$, Yashoda Mittal ${ }^{2}$,Talembedu Usha1 ${ }^{1}$, Dharmendra Kumar ${ }^{2}$, Ranjani Srinivasan $^{2}$, Laxmikant Vashisth ${ }^{1}$,
} Biplab Bhattacahrgae ${ }^{3}$ and Madhugiri Bhojangarao Nagaveni ${ }^{2}$

\begin{abstract}
${ }^{1}$ Maharani Lakshmi Ammanni College For Women, DBT-BIF center Malleswarm’ Bangalore -560012, India; ${ }^{2}$ Pt. LMS Govt. P.G College, Rishikesh, HNB Garhwal University,Srinagar, Pauri, Garhwal, India; ${ }^{3}$ Institute of Computational Biology, Bangalore, India; Sushil Kumar Middha - Email: sushil.middha@gmail.com; *Corresponding author
\end{abstract}

Abstract:

Received May 03, 2009; Revised June 23, 2009; Accepted August 23, 2009; Published August 26, 2009

Herbs are the base used for treatment in Ayurveda. We describe a database named Phyto-Mellitus with information on plants traditionally used for diabetes with their chemical constituents. The active principles of these plants are antioxidant and free radical scavenging.

Availability: http://www.bicmlacw.org/bt/

Keywords: Diabetes, Database, Medicinal plants, HTML, Citations/literature survey.

\section{Background:}

Ayurveda (In Sanskrit "knowledge of life" or "knowledge of longevity") has now spread beyond India to other countries like, Sri Lanka, Malaysia, Mauritius, South Africa, Japan, Russia,Europe, and North America. [1]. Herbs are commonly used for treatment in Ayurveda. Ethnobotanical studies of traditional herbal remedies used for diabetes around the world, have identified more than 1,200 species of plants with hypoglycemic activity [2]. The pharmacopoeia of India is especially rich in herbal treatments for diabetes. Diabetes mellitus is a complex disorder that is characterized by hyperglycemia, resulting from malfunction in insulin secretion and action. Insulin malfunction is caused by impaired metabolism of glucose, lipids and protein [3]. Medicinal plants used to treat hypoglycemic or hyperglycemic conditions are of considerable interest for ethno-botanical community as they are recognized to contain valuable medicinal properties in different parts of the plant and a number of plants have shown a varying degree of hypoglycemic and antihyperglycemic activity [4]

The objective of this database is to conduct a search of the published literature, on the use of Ayurvedic medicine/therapies for the treatment of health conditions. The basis of this database is, to check chemical compounds present in medicinal plants, with reference to their citations. A broad search of Ayurvedic medicine/therapies showed that there was sufficient literature to support a systematic review of these plants for the treatment of diabetes. Diabetes is a common illness. Many traditional medical systems have developed strategies to treat this condition. This database is to provide a platform for individuals, professionals and R\&D organizations to utilize and harness the alternative medicines, capable to cure incurable diseases.

Methodology:

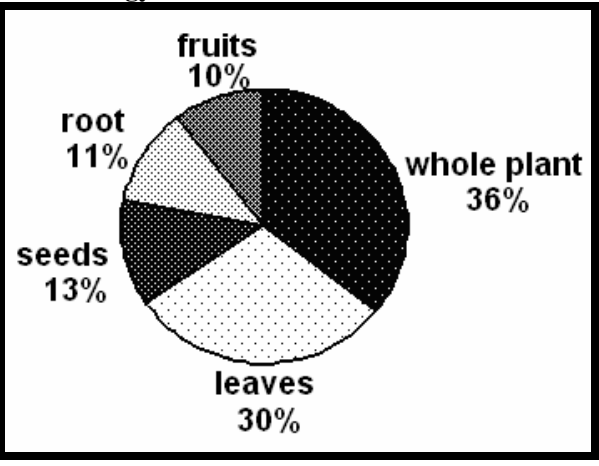

Figure 1: Distributed data as per their therapeutic use

\section{Construction of Phyto-Mellitus}

PhytoMellitus is constructed using HTML and can be accessed at http://www.mlacw.org/bt/. Data were collected from various literature sources such as,PubMed [5],ScienceDirect [6], Mary Ann Liebert [7],BlackWell Synergy[8], IngentaConnect [9], Scirus [10], Bentham Publishers [11], Wiley journals [12] and others. A panel of technical experts representing diverse disciplines was established to advice us throughout the preparation of this database. A number of databases were searched: MEDLINE®,HealthSTAR, EMBASE ${ }^{\circledR}$, Allied and Complementary Medicine ${ }^{\mathrm{TM}}$, MANTIS ${ }^{\mathrm{TM}}$, BIOSIS Previews ${ }^{\circledR}, \mathrm{CAB}$ HEALTH, and CINAHL ${ }^{\circledR}$. For searching we used the MeSH terms "Diabetes" or "chemical constitutes" combined with the botanical names of different herbs commonly used in Ayurvedic treatment. In addition, a strategy was developed to identify and retrieve literature from all over India. As part of this, several Indian journals were used to gather information. Additional articles were obtained from supplemental searches which focused on the Ayurvedic herbs, most often used for diabetes, from review articles, and from 71 citations of articles. All titles, abstracts, and articles were reviewed by two reviewers, and all disagreements were resolved by consensus. Data was collected using screening forms that we developed for this purpose. We analyzed the data regarding the general characteristics of medicinal plants from the Ayurvedic literature and used this information to select a topic for a focused review.Phyto-Mellitus includes 250 species, described to possess medicinal properties against diabetes. The complete list of 250 species can be found at http://www.mlacw.org/bt/plants.htm. The database can be accessed alphabetically using genus name for information on specific plants. A screen-shot of the Phyto-Mellitus is given in Figure 1. From the collected data, $36 \%$ were whole plants, $30 \%$ leaves, $13 \%$ seeds, $11 \%$ roots, and $10 \%$ fruits. 


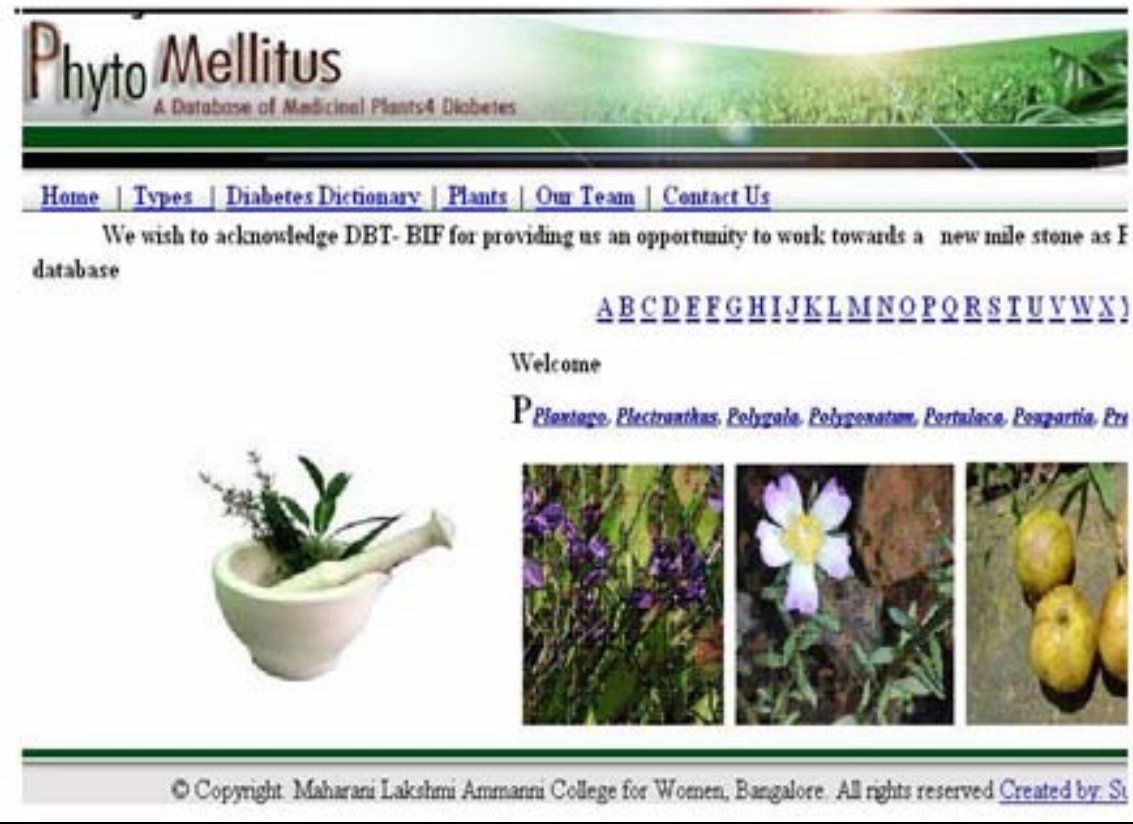

Figure 2: A screen shot of $\mathrm{P}$ record entry in Phyto-Mellitus is shown

\section{Description of the evidence}

More than 1000 articles were searched and considered in the preparation of this database (given in reference section of database as link to PMID). Maximum annotated studies came from the different published literatures. In terms of interventions, there was no study that tested Ayurveda as a system of care; from all tested herbs. Each and every data given in databases is considered only after a thorough curation process. There are several existing databases for information on plants used in diabetes. Our database is regularly updated with chemical constituents of these plants with direct link to original papers which facilitates easy access that has not been provided in any other existing databases. In this database, we are planning to include all herbal research in the field of diabetes.

\section{Utility}

Empirical evidence of efficacy for this database for diabetes would be helpful to health care providers in managing diabetic patients. It is also useful in identifying areas for future research in providing a quick review on the number of plants and plant parts for diabetic research for the benefit of scientific community.

\section{Future development}

Chemical structures of the plants with their IUPAC nomenclature and bio-energetic of different compounds will be incorporated. Continuous updates shall be released to include other plants of medicinal value. We plan to develop provisions to search the database, to identify plants of interest using keywords.

\section{Acknowledgments}

This research has been carried out in Maharani lakshmi Ammanni College For Women, DBT- BIF facility under BTIS (Biotechnology information system), DBT (Department of biotechnology), Ministry of Science and Technology, Government of India, India. We would also like to thank Dr. T. L. Shantha, director of MLACW for her moral support all through the work. The authors are also grateful to whole scientific community for their contribution towards science and Pt. LMS Govt. P.G College, Rishikesh.

\section{Conflict of interest}

The authors have no conflicts of interest to declare.

References:

[1] C Elder, Altern. Ther. Health. Med. 10:44 (2004) [PMID: 14727499].

[2] A Chopra, VV Doiphode, Med. Clin. North. Am. 86:75 (2002) [PMID: 11795092].

[3] KG Alberti, PZ Zimmet, Diabet. Med. 15:539 (1998) [PMID: 9686693].

[4] JK Grover et al., J. Ethnopharmacol. 81:81 (2002) [PMID: 12020931].

[5] http://www.ncbi.nlm.nih.gov

[6] http://www.sciencedirect.com

[7] http://www.liebertpub.com

[8] http://www.blackwellsynergy

[9] http://www.ingentaconnect.com/content

[10] http://www.scirus.com/srsapp/

[11] http://www.bentham.org

[12] http://www3.interscience.wiley.com/cgi-bin/home

Edited by $P$. Kangueane

Citation: Middha et al., Bioinformation 4(2): 78-79 (2009) License statement: This is an open-access article, which permits unrestricted use, distribution, and reproduction in any medium, for noncommercial purposes, provided the original author and source are credited. 